\title{
O EROTISMO EM “A OBSCENA SENHORA D”, DE HILDA HILST
}

\author{
THE EROTICISM IN “A OBSCENA SENHORA D”, BY HILDA HILST
}

\section{EL EROTISMO EN “A OBSCENA SENHORA D”, DE HILDA HILST}

\author{
Ana Clara Costa \\ Graduada em Letras pelas Faculdades Integradas de Jaú \\ E-mail: costa_anaclara@hotmail.com \\ Marcelo Mott Peccioli Paulini \\ Doutor em Teoria e História Literária pela Unicamp \\ Professor no curso de Letras das Faculdades Integradas de Jaú \\ E-mail: mpaulini@uol.com.br
}

\section{RESUMO}

O erotismo é um fenômeno distintivo da espécie humana. Suas manifestações são objeto de estudo das mais diversas áreas, como a neurociência, a psicanálise e a literatura. Esse tema, complexo de ser definido e esmiuçado, é de suma importância por ser inerente ao ser humano. E o interesse quanto ao erótico não é menor na área da literatura; está presente nas mais diversas obras e a necessidade de estudo surge aos olhos de pesquisadores. Não é diferente do que acontece quando se tem contato com a vasta obra da escritora Hilda Hilst, em especial "A obscena senhora D". O presente estudo analisa essa novela a partir algumas teorias sobre o fenômeno erótico.Para o cumprimento desse objetivo foram utilizados os seguintes procedimentos metodológicos: a) pesquisa teórica a fontes bibliográficas, livros, teses e dissertações; b) pesquisa de fontes paralelas e internet. O estudo evidenciou a consonância do texto literário de Hilda Hilst, através do discurso narrativo d' A obscena senhora D, com modernas e sofisticadas concepções de erotismo.

Palavras-chave:Erotismo.Erotismo na literatura. Hilda Hilst.

\section{ABSTRACT}

Eroticism is a distinctive phenomenon of the human species. Its manifestations are the subject of study of several areas, such as neuroscience, psychoanalysis and literature. This theme, complex to be defined and scrutinized, is of paramount importance by its inherence to human beings. The interest in the erotic is not low in the area of literature, it is present in several works and the need to study appears in the eyes of researchers. It's no different from what happens when you have contact with the vast work of the writer Hilda Hilst, especially "A obscena Senhora D". The present study analyzes this novel from some theories about the erotic phenomenom. To fulfill the objective, the following methodological procedures were used: a) the theoretical search of literature sources, books, theses and dissertations; b) research of parallel and internet sources. The study evidenced the consonance of Hilda Hilst's literary text, through the "A obscena senhora D" narrative discourse, with modern and sophisticated conceptions of eroticism.

Key-words: Eroticism.Eroticism in Literature. Hilda Hilst. 


\section{RESUMEN}

El erotismo es un fenómeno distintivo de la especie humana. Sus manifestaciones son objeto de estudio en diversas áreas, como la neurociencia, el psicoanálisis y la literatura. Este tema, complejo de definir y detallar, es extremadamente importante porque es inherente al ser humano. Y el interés por lo erótico no es menor en el área de la literatura; Está presente en varios trabajos y la necesidad de estudio surge a los ojos de los investigadores. No es diferente de lo que sucede cuando tienes contacto con el vasto trabajo de la escritora Hilda Hilst, especialmente "A obscena senhora D". El presente estudio analiza esta novela a partir de algunas teorías sobre el fenómeno erótico. Para lograr este objetivo, se utilizaron los siguientes procedimientos metodológicos: a) investigación teórica a fuentes bibliográficas, libros, tesis y disertaciones; b) búsqueda de fuentes paralelas e internet. El estudio evidenció la consonancia del texto literario de Hilda Hilst, a través del discurso narrativo de 'A obscena senhora D", con concepciones modernas y sofisticadas del erotismo.

Palabras clave: Erotismo. Erotismo en la literatura. Hilda Hilst.

\section{INTRODUÇÃO}

Assistindo a uma entrevista da escritora brasileira Hilda Hilst, surgiu a curiosidade de conhecer suas obras, em especial aquelas que de alguma maneira chocaram o público.

“A obscena senhora D" mostrou-se uma narrativa interessantíssima e desafiadora. Com uma escrita peculiar, o texto mostra o fluxo de consciência da narradora-personagem, que incessantemente absorve a fala de outras personagens e se constrói diante de uma quantidade enorme de dúvidas após a morte do marido.

A partir docomportamento repleto de arrebatamentos eróticos da personagemnarradora, foi natural recorrermos a Battaile, Marcuse, Lacan, e outros teóricos do erotismo para explicar diversas passagens da obra. Podemos citar como alguns desses comportamentos: o sexo como conforto e, posteriormente, na mesma medida, insuficiente. E o sagrado, em sua relação com o erótico, como busca para o preenchimento de indagações metafísicas. Ainda nesse âmbito de estudo, foi possível assimilar a relação entre o erotismo, o sagrado e a morte, temas essenciais para a compreensão de "A obscena senhora D".

Com isso, finalmente, nosso trabalho tem por intuito analisar a narrativa escolhida destacando o aspecto teórico do erotismo. Destacamos também que, ao longo de todo este estudo, apresentaremos interpretações e análises e estabeleceremos possíveis diálogos com textos teóricos e críticos.

72

RELEDUC | ISE | v. 2 | n. 2 | ago. 2019 


\section{O EROTISMO}

\subsection{O que é erotismo}

Inerente ao ser humano, o erotismo faz-se presente em grande parte dos textos literários. E desde a antiguidade, a literatura mostra-se um espaço privilegiado para a manifestação do erótico. Nos estudos sobre o fenômeno erótico, fontes mais remotas são utilizadas, como os mitos gregos, que metaforizados, se transformam em conceitos consistentes do erotismo e seus prognósticos. Nesse escopo das lendas gregas, temos como figura principal Eros, deus do amor, o responsável pela origem e definição do termo erotismo.

Diversos são os teóricos que sentiram a necessidade de definir o tema. Segundo Lúcia Castello Branco (1987),fazê-lo é um caminho suntuoso:

(...) traduzir e ordenar, de acordo com as leis da lógica e da razão, a linguagem cifrada de Eros, seria caminhar em direção oposta ao desejo, ao impulso erótico, que percorre a trajetória do silêncio, da fugacidade e do caos. O caráter incapturável do fenômeno erótico não cabe em definições precisas e cristalinas - os domínios de Eros são nebulosos e movediços. (BRANCO, 1987, p. 7)

O mito grego de Eros diz que o erotismo pode ser definido através de seu próprio movimento; e o mesmo acontece com a sua própria definição, que não pode ser feita senãoatravés do caminho que o próprio Eros percorre. Esse movimento deve ser trilhado através de duas principais vias, que são a de conexão com a vida (e consequentemente com a morte) e a conexão com Deus, ou com o Cosmo (dependerá da religião a definição mais apropriada).

Branco (1987), afirma que a concepção de "impulso erótico" numa busca pela plenitude aparece desde a Antiguidade Clássica. Em um dos textos mais antigos sobre erotismo, o filósofo grego Platão, no diálogo O banquete, apresenta essa concepção. No banquete em que se passa a ação, Aristófanes, no seu elogio a Eros, conta que antes da existência desse ser, havia três sexos na natureza humana: eram os masculinos, os femininos e os andróginos. Os seres andróginos eram redondos e possuíam quatro mãos, quatro pernas, duas faces, dois genitais, quatro orelhas e uma cabeça. Por serem muito poderosos, eles desafiaram os deuses, e Zeus, por sua vez, decidiu cortar cada um deles em dois. Após a mutilação, esses seres se tornaram fracos e também úteis, pois perdiam seus poderes, mas poderiam servir aos deuses. 
Desde que sofreram essa divisão, esses seres mutilados passaram a procurar suas metades. Assim que se encontravam, eles se abraçavam com desejo de se unir novamente. A partir desse desejo de união, de busca pela sua outra metade e de recuperação da antiga perfeição, é que se define o impulso erótico. Além disso, na fala de Aristófanes, a homossexualidade é legitimada, pois a busca da completude através do outro é independente do sexo do ser.

Ainda na definição de erotismo, Bataille (1987) diz tratar-se deuma busca interior e não exterior, porque o desejo vem de dentro do ser. Porém, ela pode ser confundida por se dirigir a um objeto que está no plano exterior. O desejo erótico, diferentemente do animal, tem como fim a busca complexa de algo incapturável e que vem do âmago do ser, o que é uma singularidade do homem.

$\mathrm{O}$ erotismo do homem difere da sexualidade animal justamente por colocar em questão a vida interior. O erotismo é, na consciência do homem, o que nele coloca o ser em questão.

(BATAILLE, 1987, p. 53)

Bataille (1987) considera o impulso do erotismo como procura de continuidade. Ele também diz que essa busca carrega consigo uma espécie de nostalgia, como já fora sugerido por Aristófanes no diálogo platônico.

\subsection{Erotismo e morte/ Eros e Tânatos}

Os impulsos eróticos levam à constante transformação e busca de algo inatingível. Inconscientemente, acredita-se que essa busca quer a completude do ser, mas tal plenitude é o que promove a eterna busca do Eros. Entretanto, como é possível chegar a essa situação estando vivo, já que, enquanto vivemos, desejamos? Somente na morte é que o ser, mesmo que involuntariamente, cessa a procura da completude e está finalmente em paz. Dessa maneira, então, Eros, deus do amor, e Tânatos, deus da morte, vivem paradoxalmente juntos.

É possível identificar várias vezes o percurso erótico desembocando na morte. O Erosmorte está presente nos mais diversos casais apaixonados da literatura, que invariavelmente morrem após vivenciarem um intenso amor; e está no mistério e medo que percorre o erótico e que, da mesma forma, permeia a morte. A literatura romântica é fértil em exemplos ilustradores dessa fusão amor-morte. 
Marcuse (1955), no livro Eros e civilização, a partir de conceitos da psicanálise freudiana, propôs que o impulso erotismo-morte não é algo natural do ser humano, mas sim causado pela vivência repressora da sexualidade. Marcuse (1955) pensou na possibilidade de desatar esse nó entre o erotismo e a morte. Isso seria possível se todas as repressões fossem extintas. Porém, com repressões vindas de todos os lados, como os regimes totalitários, as repressões religiosas e os conceitos moralizantes, essa libertação do erótico em relação à morte é praticamente impossível.

Bataille (1987) discorda de Marcuse (1955) e declara que o impulso Eros-morte é algo natural e inerente ao ser humano. Ele explana sua teoria através da origem da vida: nas reproduções sexuadas e assexuadas, antes de uma vida se originar, uma morte anterior é necessária. Na reprodução sexuada, o óvulo e o espermatozoide morrem para dar origem a um feto. Na reprodução assexuada, a célula se divide em duas, e de um núcleo, que posteriormente deixará de existir, se originam duas novas células. Bataille (1987) constrói toda a sua concepção de erotismo através da fusão morte e erotismo. Para ele, essa busca contínua de Eros é uma forma de superar a finitude. Contudo, nessa eterna busca de completude nunca atingida, a chegada inevitável para os seres é a morte.

Para Bataille (1987), a vida humana tem como base o trabalho e a razão, porém o trabalho não supre os anseios do homem. Além disso, existe também a violência inerente ao ser humano, formada por um impulso natural ligado ao exceder-se e que está inseparavelmente ligada à humanidade. Ela relaciona-se, da mesma forma, com o erotismo e a morte. É o trabalho que age para com os homens como objeto que refreia e adia o prazer.

\title{
2.3 Erotismo e o sagrado
}

Bataille (1987) divide o erotismo, dependendo de como é vivido, em três tipos diferentes. São eles: erotismo dos corpos, o dos corações e o erotismo sagrado. O erotismo dos corpos é aquele que responde à descontinuidade individual, de todo e cada ser, algo que se vivencia sozinho e com o próprio corpo. O erotismo dos corações está ligado a outros corpos no momento em que se encontra a paixão no sentido violento, que gera caos, confusão. O erotismo sagrado é uma busca da continuidade perante a descontinuidade de dois seres. Nessas três instâncias, o ser humano está sempre em busca da sua completude e da paz eterna. O ser está sempre tentando se religar, o que desemboca no que é sagrado e,

\author{
75 \\ RELEDUC | ISE | v. 2 | n. 2 | ago. 2019
}


consequentemente, religioso. Até mesmo em seu sentido etimológico, a palavra tem igual significado do princípio do impulso erótico: a palavra religião vem do latim religare, que quer dizer "atar firmemente".

Mesmo na Igreja Católica encontramos elementos simbólicos de cunho erótico: a oferenda do corpo e do sangue de Cristo como comida e bebida para os devotos e participantes do momento da comunhão. Bataille (1987) explica que o erotismo sagrado fica mais claro de ser compreendido quando essa continuidade do ser passa a ser uma procura de algo que foge do que é momentâneo, algo que garanta uma espécie de eternidade, de um todo completo.

[...] a ideia de erotismo sagrado é menos familiar. A expressão, aliás, é ambígua na medida em que todo erotismo é sagrado, mas encontramos os corpos e os corações sem entrar na esfera sagrada propriamente dita. Ao passo que a busca de uma continuidade do ser levada a cabo sistematicamente para além do mundo imediato designa uma abordagem essencialmente religiosa.

(BATAILLE, 1987, p. 39)

Ainda assim, a ligação que tem o erotismo com o sagrado não necessariamente converge em um deus. O sagrado consiste nessa busca de continuidade, ou seja, um ser descontínuo, limitado, incompleto, procurando a continuidade absoluta. O cristianismo procurou sempre utilizar-se da transformação da descontinuidade egoísta para a continuidade visada pelo amor a Deus.

O mundo divino teve de mergulhar num mundo de coisas. Este aspecto múltiplo é paradoxal. A vontade resoluta de confiar tudo à continuidade teve seu efeito, mas este primeiro efeito teve de compor com um efeito simultâneo no outro sentido. O Deus cristão é a mais bem acabada construção feita a partir do sentimento mais nocivo, o da continuidade. A continuidade é dada na superação dos limites. Mas organizar o que por essência é desordem é o efeito mais constante do movimento a que dei o nome de transgressão.

(BATAILLE, 1987, p. 144)

Como anteriormente foi dito, o erotismo é um impulso emitido para a busca e continuidade do ser. Nesse sentido, identificamos mais um ponto que desemboca no sagrado. Quando o ser está contínuo, aliás, a continuidade faz parte de sua origem, a morte não o anula, pelo contrário, o desperta. Bataille (1987) explica que a morte não atinge o ser, mas o manifesta, como no sacrifício religioso. Na ação erótica há desnudamento da vítima, já no 
sagrado há o sacrifício da vítima. Os participantes do sacrifício religioso promovem um ritual no qual a morte é revelada, e para isso dá-se o nome de sagrado.

Para Bataille (1987), o sagrado é o sacrifício da descontinuidade de um ser que se tornará contínuo, através de um ritual:

O sagrado é justamente a continuidade do ser revelada aos que fixam sua atenção, num rito solene, sobre a morte de um ser descontínuo. Há, em decorrência da morte violenta, ruptura da descontinuidade de um ser: o que subsiste e que, no silêncio que cai, experimentam espíritos ansiosos, é a continuidade do ser, a que a vítima é devolvida. (BATAILLE, 1987, p. 45)

Assim, a divindade é uma espécie de fruto, consequência do sagrado, pois sendo divino possui a continuidade do ser. Sua experiência como ser é fornecida pela sua continuidade, ao mesmo tempo em que a revela.

\subsection{Erotismo e a mulher}

A mulher tem, em todo impulso erótico, papéis eróticos singulares, na verdade, reservados ao ser feminino. Vemos que no ritual erótico, a vítima que é sacrificada é o feminino, e o sacrificador é o masculino. Nesse movimento, temos por fim, a passividade da postura feminina e o masculino como a postura ativa.

De acordo com Bataillle (1987), é o ser da parte feminina que se dissolve no ato erótico. A figura masculina tem a função de preparar a dissolução feminina para a fusão onde esses seres se misturam.

Na fusão Eros-morte, o papel feminino também é peculiar como elemento do impulso erótico. Segundo Branco (1984), a mesma mulher que aparece na literatura como elemento gerador da vida, protetora do filho, é também o ser que traz a morte ao mundo dos homens. Vejamos Eva, figura feminina: é ela quem morde a maçã e provoca a expulsão do Éden. É Pandora quem abre a caixa e deixa escapar os males para a humanidade. Até mesmo na representação da morte, são várias as ilustrações e pinturas que a simbolizam como um ser feminino.

Essa intimidade da mulher com Tânatos parece ter influído também na representação da morte como ser feminino, presente no imaginário de diversos povos. A literatura ocidental está repleta de exemplos em que a morte é figurada como uma mulher, convenientemente trajada no estilo de sua época. Etérea e espiritual para os simbolistas, sensual e misteriosa para os românticos, ou sofisticadamente cruel para os decadentistas, a morte 
encarna, em diversas culturas, os diversos atributos que se convencionaram como femininos.

(Branco, 1984, p. 40)

\section{APRESENTAÇÃO DA OBRA “A OBSCENA SENHORA D”}

Publicada em 1982, a novela de Hilda Hilst trata da história de Hillé, uma senhora de sessenta anos que decide viver no vão de uma escada. A mudança da morada tem como pretensão a busca mística através do "Menino-porco", uma referência a Deus. Hillé perdera recentemente seu marido e sempre vivera isolada, enxovalhada por parentes e vizinhos devido a seus costumes um tanto bizarros, como andar nua, por exemplo.

Antes de seu marido morrer, ele lhe dera o apelido de Senhora D. A letra "D" remete à "derrelição", o mesmo que desamparo, abandono. Abandono esse que faz clara referência à falta de Deus.

Para muitos críticos, A obscena senhora D é o cume da produção de Hilda Hilst. Em sua fase mais madura, é nele que Hilst mistura suas maiores e melhores características: erotismo, misticismo e fluxo de consciência. Porém, falar que a obra de Hilda se reduz apenas a essas características seria um erro. Há muito mais que envolve a densa obra da autora, e mesmo o que permeia esses vieses tem muito mais alcance para apenas taxá-los como sendo uma coisa ou outra. Enfim, podemos falar que a obra de Hilda Hilst é extremamente profunda e difícil de se desvendar.

A escrita hilstiana sempre esteve à frente de seu tempo, tendo dado e procurado explicações para os problemas do mundo muito diferentes das percepções habituais, o que a afastou do grande público. Sobre isso, Nelly Novaes Coelho (1980) diz:

[...] Diz-se que ela não vende porque o leitor de hoje, na maioria, não está sintonizado na faixa do pensar. O pensar para além da epiderme, o pensar para além dos limites em que nós temos que viver o dia-a-dia que é tão importante. (...) dizem: "é uma escritora hermética". Não é hermética, a partir do momento em que a gente se sintoniza com a dimensão em que ela está vibrando, pensando, vivendo, em que está enfim, fluindo.

(COELHO, 1980, p. 158-159)

Além das questões acima, temos nessa narrativa traços de ironia e ideologia política. $\mathrm{Na}$ forma como a trama é conduzida, poderemos perceber que os vizinhos da protagonista são o retrato dos "atoleimados" da sociedade. Nessa obra quase que autobiográfica, Hilda mediocriza o senso comum e a cegueira diante das questões da humanidade. Vemos então a 
relação de Hilda com Hillé - revoltadas contra o senso e o lugar comuns e sempre em busca do que vai além do que olhos veem.

Uma das explicações de Hilda não ser tão lida é tida pela forma "hermética" que muitos caracterizam sua escrita. Sobre isso, a autora diz em uma entrevista:

Quando me perguntam por que escrevo dessa forma que as pessoas não entendem, e por que é tão complexo tudo, então eu digo, mas meu Deus, é o processo da vida que é tão complexo. Eu não saberia simplificar esse processo para ser mais compreensível, é o meu próprio processo dificultoso de existir que faz com que venha essa avalanche de palavras, umas assim barrocas demais, e que tudo seja misturado. Porque eu acho que a vida transborda, não existe uma xícara arrumada para conter a vida!...

(DINIZ, 2013, p. 89-90)

“A obscena senhora D” desencadeou os livros posteriores, claramente pornográficos. São compostos por palavrões crus e de baixo calão, além deconter a constante e escancarada representação erótica que Hilda põe em jogo na narrativa como parte do processo para a compreensão de seu emaranhado de dúvidas.

Um dos recursos que Hilda utiliza na composição de seus textos é o fluxo de consciência dos personagens, que, misturado com as falas e com a pontuação ajustada de acordo com uma sintaxe pessoal (e não seguindo a norma padrão da língua) constroem sua peculiaridade estilística. Em A obscena senhora D, a voz de Hillé,é expressa durante toda a narrativa, de forma ininterrupta. Os diálogos dos outros personagens perpassam sua mente. De acordo com Branco (1991), notam-se também características da escrita feminina, cheia de respiros, sussurros e elementos fortemente orais.

Outra grande característica dessa obra é a presença mesmo se tratando de um texto em prosa. Alcir Pécora (2001), na nota de organizador da edição de A obscena senhora D da editora Globo, aponta que através dos versos e rimas ali presentes transparece a poesia contida na prosa. Por outro lado, a dramaticidade também está presente devido aos diálogos e ao intenso fluxo de consciência da personagem. Têm-se então a fusão de dois gêneros.

\section{O MISTICISMO ERÓTICO DA SENHORA DERRELIÇÃO}

A exploração erótica de “A obscena senhora D” é marcada pela busca do sagrado. Há no erotismo uma busca excessivamente densa, sem fim, uma constante insatisfação, resultado dos seres mutilados que estão sempre procurando suas metades. Dessa mesma forma,

$$
\text { RELEDUC | ISE | v. } 2 \text { | n. } 2 \text { | ago. } 2019
$$


insatisfeita, é que a personagem apresenta suas dúvidas sobre a morte e o sagrado. Refere-se a Deus com o epíteto ultrajante de "Porco-Menino Construtor do Mundo". Provavelmente essa associação se deva à blasfêmia com que a personagem Hillé quer provocar a divindade.

A morte já é tematizada em A obscena senhora D pelo poema que inicia a obra, publicado posteriormente em Cantares de perda e predileção - Canto XV. Nele, o eu lírico fala sobre a morte e a preparação para ela.

\section{Canto XV}

Para poder morrer

Guardo insultos e agulhas

Entre as sedas do luto.

Para poder morrer

Desarmo as armadilhas

Me estendo entre as paredes

Derruídas.

Para poder morrer

Visto as cambrarias

E apascento os olhos

Para novas vidas.

Para poder morrer apetecida

Me cubro de promessas

Da memória.

Porque assim é preciso

Para que tu vivas.

(HILST, 2001, p. 15) 
Há presente no poema um erotismo ligado a uma clara atração pela morte - não que ela seja algo fácil, pois é preciso abrir mão da vida, afinal, para se chegar a ela. Porém, a morte não é vista como o fim da uma jornada, o aniquilamento do ser; ao contrário, ela é vista como um processo para a transcendência.

Depois que Ehud, o marido morre, ela perde definitivamente o contato com a vida. Tudo o que é vivo, para Hillé, é o caminho oposto ao de sua busca constante por explicações. Há uma passagem em que ela fala sobre os peixes de seu aquário, em que deixa evidente sua aversãopelo que é vivo:

Quando Ehud morreu morreram também os peixes do pequeno aquário, então recortei dois peixes pardos de papel, estão comigo aqui no vão da escada, no aquário dentro d'água, não os mesmos, a cada semana recorto novos peixes de papel pardo, não quero mais ver coisa muito viva, peixes lustrosos não, nem gerânios maçãs romãs, nem sumos, suculências, nem laranjas $(\ldots)$

(HILST, 2001, p. 19)

O que Hillé busca está além do contato com a vida, por isso ela mantem uma relação estreita com o sagrado. O fato de Hillé recortar peixes em um papel pardo é algo que substitui a vida, mas uma vida da qual ela não quer participar, apenas lembrar. E é apenas através do cultivo das suas memórias, de Ehud e de seus pais, que ela vivencia os seus dias. Por meio das lembranças, ela consegue ter algum tipo de alegria, sem os problemas, os medos e as inseguranças que uma vida efetivamente vivida pode normalmente trazer.

Em meio a tantas recordações longínquas, Hillé sente falta do que relembra e sofre com a velhice do próprio corpo. Outro aspecto significativo no seu processo de desligamento da vida cotidiana é a decadência da beleza, o medo da "secura" da própria vida.

(...) Memórias, velhice, tateio nadas, amizades que se foram, objetos que foram acariciados, pequenas luzes sobre eles nesta tarde, neste agora, cercoos com minha pequena luz, uma que me resta, ínfima, amarela, e eles continuam estáticos e ocos, sobre as grandes mesas, sobre as arcas, sobre a estante escura, sonâmbula vou indo, meu passo pobre, meu olho morrendo antes de mim, a pálpebra descida, crestada, os ralos cabelos, os dentes que parecem agrandados, as gengivas subindo, procuro um naco de espelho e olho para Hillé sessenta, Hillé e emoções desmedidas, fogo e sepultura, e falas falas, desperdícios a vida foi, Hillé, como se eu tocasse sozinho um instrumento, qualquer um, baixo, flautim, pistão, oboé, como se eu tocasse sozinho apenas um momento da partitura, mas o concerto todo onde está?

(HILST, 2001, p. 71)

81

RELEDUC | ISE | v. 2 | n. 2 | ago. 2019 
Na concepção platônica, no discurso de Aristófanes, acerca da busca erótica, o ser precisa do outro para se sentir completo. Já na concepção de Bataille (1987), essa completude é atingida através da morte, que por sua vez, é aspirada por Hillé:

[...] morta sim é que estarei inteira, acabada, pronta como fui pensada pelo inominável tão desrosteado, morta serei fiel a um pensado que eu não soube ser, morta talvez tenha a cor que sempre quis, um vermelho urucum, ou um vermelho ainda [...] (HILST, 2001, p. 79)

A dualidade Eros e Tânatos é o choque entre o amor pela vida e a busca pela transcendência, tema caro à autora. A sexualidade é, ao mesmo tempo, degradante e representativa da vida do ser. A postura de Hillé quanto ao ato sexual começa a mudar a partir do momento em que ela se muda para a escada, ou seja, o momento da procura pelo transcender. O marido, que passa a se sentir rejeitado, questiona Hillé sobre o seu súbito desinteresse pelo sexo:

[...] e você gostava, me lembro das noites que você fazia o café, depois o roupão branco, teus peitos apareciam, eles não caíram os teus peitos, o que é que você faz, hen? escute Senhora $\mathrm{D}$, estou descendo a escada, bem devagar, está ouvindo os meus passos? [...] então estou descendo, escuta, também posso foder nesse ridículo vão de escada...

(HILST, 2001, p. 22)

A partir do momento em que Hillé passa a não mais sentir no amor físico a possibilidade da completude, ela responde negativamente ao convite do sexo. Hillé quer escapar de seu corpo, e talvez como forma de punição, a fuga do prazer é o que encontra. Também por não encontrar significado mais no ato é que ela desconhece o sentido de amar carnalmente.

[...] não venha, Ehud, posso fazer o café, o roupão branco está aqui, os peitos não caíram, é assustador até, mas não venha, Ehud, não posso dispor do que não conheço, não sei o que é corpo mãos boca sexo, não sei nada de você Ehud a não ser isso de estar sentado agora no degrau da escada, isso de me dizer palavras, nunca soube nada, é isso nunca soube você se deitava comigo, mesmo não sabendo [...] (HILST, 2001, p. 23)

Coelho (1993) aponta queo erótico começa a ser vivenciado a partir do momento em que Hillé inicia sua busca pelo sagrado:

82

RELEDUC | ISE | v. 2 | n. 2 | ago. 2019 
Identificando o sexo com a animalidade (conforme milenar tradição religiosa), Hillé o recusa a partir do momento em que pretende descobrir e assumir sua essência humana através do conhecimento de Deus. Mas essa recusa não tem grandeza, é obscura e dolorosa porque fundida à animalidade do sexo manifesta-se a sua essencialidade e o confuso pressentimento de que é nela que o ser tem suas raízes. (COELHO, 1993, p. 219)

É possível perceber em diversas passagens do livro a confusão que a falta de contato físico, ligado à procura desesperada por um Deus ou por algo erótico que lhe complete, causa à Hillé. Ora ela sente falta do marido, ora faz perguntas intermináveis. Além disso, com a morte de Ehud, o sexo fica ainda mais distante, e a força de Eros volta-se para a busca do sagrado.

O que mostra a ideia da completude platônica n'O banquete, parece ser ilustrado pela autora em uma das diversas confusões que sente. Os peixes, feitos em papel pardo, parecem durar mais quando têm seus pares: "Convém que sejam dois peixes de papel porque se recorto apenas um ele se desfaz mais depressa, já notei, será possível que até as coisas precisem de seu duplo? mais depressa no fosso se sozinhas?” (HILST, 2001, p. 81).

Hillé, ao percorrer a estrada em busca da completude, por diversas vezes, tem uma relação erótica com Deus. Assim como Santa Teresa D’Avila, ela sente necessidade de vivenciar uma relação sexual, vivendo assim uma espécie de teofagia erótica. Aliás, a personagem mesmo se autointitula "téofaga incestuosa". Em um dos trechos em que vemos essa relação, é possível também fazer clara conexão com o ritual de comunhão da missa católica: "Engolia o corpo de Deus a cada mês, não como quem engole ervilhas ou roscas ou sabres, engolia o corpo de Deus como quem sabe que engole o Mais...” (HILST, p. 19). Dessa forma, Hillé, pretende estar muito próxima do objeto divino, Deus, para entendê-lo, sabê-lo. Entretanto, nem mesmo através desse ritual chega ao estado máximo de superação: "Engolia o corpo de Deus, devo continuar engolia porque acreditava, mas nem porisso compreendia..." (HILST, 2011, 19).

As necessidades de Hillé, tanto eróticas quanto sagradas, ou erótico-sagradas, se voltam para um ponto, especificamente: compreender. Nessa busca, ela chega a estabelecer que Deus nada tem a ver com o mundo, ou "porco-mundo", como denomina. Diversas vezes fala que a terra está cheia de tristeza, enquanto que a divindade, o "menino-porco" está a salvo. A divindade então, ela nunca encontra:

83

RELEDUC | ISE | v. 2 | n. 2 | ago. 2019 
Te busquei, Infinito, Perdurável, Imperecível, em tantos gestos palavras passos, em alguma boca fiquei, curva sinuosidade, espessura, gosto, que alma tem essa boca? E os gestos, meu Deus, como os tomei para mim: lerdos frívolos pausados recebendo o mundo, afoitos grotescos. (HILST, 2001, p. 76)

Hillé se revolta por não conseguir chegar as suas respostas e também por não tocar no sagrado. É justamente por essa revolta que apela ao erótico. Ela transgride a ordem, usando vocabulário obsceno e ficando nua. Sua postura transgressora é tachada pelos vizinhos como a de uma louca. Sua casa é conhecida como "Casa da porca", um lugar maldito onde uma louca questiona Deus e diz injúrias. Para Hillé, os vizinhos não passam de seres vulgares que vivem a margem do senso-comum:

Não pactuo com as gentes, com o mundo, não há um sol de ouro no lá fora, procuro a caminhada sem fim, te procuro, vômito, Menino-Porco (...) um dia me disseram: as suas obsessões metafísicas não nos interessam, senhora D, vamos falar do homem aqui agora. que inteligentes essas pessoas, que modernas, que grande cu aceso diante dos movietones, notícias quentinhas, torpes, dois ou três modernosos controlando o mundo, o ouro saindo pelos desodorizados buracos, logorreia vibrante moderníssima.

(HILST, 2001, p. 25-26)

Somente quando está à beira da morte, ao fim da história, é que vemos Hillé finalmente atingindo o nirvana. Nesse momento ela compreende que Deus não quer a compreensão humana e por isso transforma o homem em um eterno desejador, justamente para que galgue o "elevar-se" e passe por esse processo.

Hillé era turva, não?

um susto que adquiriu compreensão.

que cê disse, menino?

o que você ouviu: um susto que adquiriu compreensão. isso era Hillé. (HILST, 2001, p.89)

Percebemos então, nas últimas palavras de Hillé, uma calmaria, calmaria essa que ocupada todos os espaços e não dá espaço para a revolta sentida antes. Conseguimos inferir também que Hillé, ao sentir que compreendeu Deus, também se sente autocompreendida. Deixa assim para trás todo o erotismo que empregava na busca do "Menino-porco".

\section{CONSIDERAÇÕES FINAIS}

84

RELEDUC | ISE | v. 2 | n. 2 | ago. 2019 
Ao longo do estudo realizado tivemos como prioridade a análise da personagem Hillé e o seu comportamento diante de suas incertezas. Constatamos, pois, que as atitudes de Hillé, desde a recusa ao sexo com o marido, até a mudança para o vão da escada são eróticas. A introspecção total da personagem e o questionamento a Deus tomam conta do seu ser. A relação erotismo, sagrado e morte fazem parte do ser humano. A personagem, numa reação atípica devido ao seu extremismo, demonstra de forma evidente os aspectos do erotismo, não singulares a ela. Bataille (1987) nos mostra que a atitude erótica é comum a todos os seres humanos, que estão sempre tentando se completar, preencher um vazio que busca o infinito.

Através desses aspectos é construída a narrativa analisada e olhando para eles pudemos entender melhor o que Hilda quis expressar com seu texto. E, através da forma como escreveu e sob o domínio de incessantes dúvidas, ousamos dizer que, na morte, onde finalmente encontrará a paz, Hillé/Hilda, deixa a derradeira prece que sempre quis mostrar (e mostrou por muitas vezes): "Livra-me, Senhor, dos abestados e dos atoleimados" (HILST, 2001, p. 90).

\section{REFERÊNCIAS}

BARTHES, Roland. O prazer do texto. Trad. J. Guinsburg. São Paulo: Perspectiva, 1996. BATAILLE, Georges. O erotismo. Trad. Antonio Carlos Viana.Porto Alegre: L\&PM, 1987. BRANCO, Lúcia Castello. O que é escrita feminina. São Paulo: Brasiliense, 1991.

BRANCO, Lúcia Castello. O que é erotismo. São Paulo: Brasiliense, 1987.

CASA DO SOL. Disponível em: <http://www.angelfire.com/ri/casadosol/vidaeobra.html>. Acesso em 15 jul.2014.

COELHO, Nelly Novaes. A poesia Obscura/Luminosa de Hilda Hilst e a "Metamorfose" da nossa época. Posfácio de Poesia (1959-1979). São Paulo: Quíron, 1980.

D’ÁVILA, SANTA TERESA. Livro da vida. Trad. Marcelo Musa Cavallari. São Paulo: Companhia das Letras, 2010.

DINIZ, Cristiano (org.) Fico besta quando me entendem - entrevistas com Hilda Hilst. São Paulo: Biblioteca Azul, 2013.

GUIMARÃES, Cinara Leite. A obscena senhora D, de Hilda Hilst, e as relações entre eros, tânatos e logos. 2007. 92 f. Dissertação (Mestrado) - Universidade Federal da Paraíba, 85

$$
\text { RELEDUC | ISE | v. } 2 \text { | n. } 2 \text { | ago. } 2019
$$


João Pessoa, 2007. Disponível em: 〈http://www.cchla.ufpb.br/ppgl/images/Cinara.pdf〉. Acesso em 15 jul.2014.

HILST, Hilda. A Obscena Senhora D. São Paulo: Globo, 2001.

LACAN, Jacques. "Deus e o gozo d'A Mulher". In: O Seminário, livro 20, mais ainda. Rio de Janeiro: Jorge Zahar, 1985.

MARCUSE, Herbert. Eros e a Civilização - uma crítica filosófica ao pensamento de Freud. Trad. Álvaro Cabral. Rio de Janeiro: Zahar, 1955.

RELEITURAS. Disponível em: <http://www.releituras.com/hildahilst_bio.asp> Acesso em 10 jul.2014. 